\title{
O ciúme romântico e os relacionamentos amorosos heterossexuais contemporâneos
}

\author{
Thiago de Almeida \\ Universidade de São Paulo \\ Kátia Regina Beal Rodrigues \\ SENAC e Colégio Sena Aires - Rio Verde, Goiás \\ Ailton Amélio da Silva \\ Universidade de São Paulo
}

\begin{abstract}
Resumo
O presente estudo pretende discorrer a respeito do ciúme romântico heterossexual, na tentativa de compreender um dos sentimentos mais presentes na vida do ser humano. Mesmo que para muitos o ciúme possa representar uma manifestação de amor, ele é, na verdade, um sentimento que produz angústia em muitos parceiros e pode atingir formas doentias, e abalar a saúde mental. Mas também é inevitável, porque em maior ou menor grau, todos estão sujeitos a ele, o que nos obriga a ficar atentos para saber elaborá-lo em favor de nossa vida amorosa. É preciso conhecer profundamente esse sentimento para que se possa compreendê-lo, e elaborarmos estratégias profícuas de enfrentamento para lidarmos com esse fenômeno.
\end{abstract}

Palavras-chave: ciúme; amor; relações homem-mulher; infidelidade

\begin{abstract}
Romantic jealousy and heterosexual contemporary loving relationships. The present study intends to discuss the heterosexual romantic jealousy, in an attempt to understand it, as one of the most present feelings in the human life. Even for many people the jealousy may represent a love manifestation, it is, actually, a feeling that produces anguish in many partners and it can reach unhealthy forms, and to affect the mental health. However, it is also inevitable, because in larger or smaller degree, all of us are subject to it, what forces us to be attentive to know to elaborate it in favor of our loving life. In order for us to understand this feeling, it is necessary to know it deeply so that we may be able to elaborate useful strategies of confrontation of this phenomenon.
\end{abstract}

Keywords: jealousy; love; man-woman relationships; infidelity

Os ciumentos sempre olham para tudo com óculos de aumento, os quais engrandecem as coisas pequenas, agigantam os anões, e fazem com que as suspeitas pareçam verdades (Cervantes)

$\mathrm{H}$ á muito tempo o ser humano se depara com preocupações sobre o ciúme, no tocante aos conflitos amorosos e com suas conseqüências para os mesmos. Por que os casais se desentendem, freqüentemente, em virtude do ciúme? Por que se separam? Por que o amor acaba? Estas e tantas outras questões que desde há muito foram formuladas, impulsionamnos na busca de respostas.

Muitos destes questionamentos estão relacionados com a questão do ciúme romântico que seria aquele que ocorre entre os casais constituídos, somente para diferenciá-lo de outras possíveis manifestações. Ao se considerar a escassez de estudos que abarquem estas e outras questões, e dada a relevância deste fenômeno, este artigo pretende propor alguns encaminhamentos para os presentes questionamentos a fim de subsidiar o trabalho do psicólogo (e outros profissionais de saúde) e das pessoas que são vitimizadas, ou ainda, que infligem sofrimentos aos parceiros devido a este tipo específico de ciúme.

Se por um lado, para muitos, o ciúme representa uma manifestação de amor, ele também pode ser considerado, por outro lado, para outras pessoas, como um sentimento que produz angústia, pode atingir formas doentias e abalar a saúde física e mental dos envolvidos direta ou indiretamente com ele. Todavia, também se pode tratá-lo como algo inevitável, porque em um maior ou menor grau, todas as pessoas estão sujeitas a ele. Há que se ressaltar também a existência de uma pluralidade de entendimentos, pelas diferentes culturas, no que se refere ao ciúme (Almeida, 2007b).

Dessa forma, quer como vítimas, ou ainda, como algozes dos parceiros, as pessoas são obrigadas a permanecer atentas 
para saber elaborá-lo em favor de sua vida amorosa, a fim de conquistarem um relacionamento amoroso com uma maior satisfação e menos conflitos desnecessários (Almeida, 2003, 2004, 2007a, 2007b; Almeida \& Mayor, 2006; Clanton \& Smith, 1998; Hintz, 2003; Melamed, 1991; Pines, 1998; Pines \& Aronson, 1983). Logo, se não nos dermos o trabalho de refletir a respeito deste tema, talvez estejamos perdendo uma preciosa oportunidade para otimizar a qualidade dos nossos relacionamentos amorosos, os quais tanto valorizamos e queremos preservar, inclusive por meio dos mecanismos do ciúme.

Há que se levar em conta que os casos de ciúme romântico que serão apresentados aqui estão longe de esgotar este conceito, estabelecer a realidade, ou mesmo generalizar as explicações para o fenômeno. Portanto, nos estudos apresentados a seguir, não se deve esperar que o ciúme romântico heterossexual explique integralmente todas as possíveis dinâmicas relacionadas. Por exemplo, muitos destes achados não podem ser generalizados para pessoas que se afiliem homoeroticamente. Porém, estes estudos auxiliam na compreensão de muitos casos similares, e, portanto, essas referências não são tão inconclusivas como se pode previamente cogitar.

Ao se considerar a escassez de estudos que abordem estas e outras questões, e dada a relevância deste fenômeno, este artigo pretende viabilizar alguns encaminhamentos para: (1) subsidiar o trabalho do psicólogo (e outros profissionais de saúde), (2) para as pessoas que são vitimizadas pelos desdobramentos do ciúme romântico (3) e ainda, para as pessoas que infligem sofrimentos aos parceiros relacionados a este tipo específico de ciúme. Assim, procuramos, primeiramente, entender o que é o ciúme romântico, quais os seus tipos, como ele se manifesta e como influencia a dinâmica dos relacionamentos conjugais.

\section{O que é o ciúme romântico?}

Entre todos os tipos de ciúme citados na literatura científica, o ciúme romântico, isto é, aquele que ocorre em relacionamentos amorosos, é um dos que tem despertado maior atenção de psicólogos e leigos. Dentre as mais diferenciadas emoções humanas, o ciúme é extremamente comum (Kingham \& Gordon, 2004). Segundo alguns teóricos, ele seria inerente, isto é, constitutivo da natureza humana de maneira que todos nós seríamos ciumentos em maior ou em menor grau. Ele pode ocorrer em quaisquer tipos de relacionamentos, mas está comumente associado aos relacionamentos amorosos (Bringle, 1995).

Pode-se dizer que mesmo quando não se trata de um namorado com vistas a um relacionamento de longo prazo, as pessoas são temerosas de que seus parceiros encontrem outros parceiros potencialmente mais atraentes e gratificantes do que elas, e dessa forma, alimentam, freqüentemente, uma insegurança afetiva (Buss, 2000; Murray \& Holmes, 2000). Conseqüentemente, por se encarar os relacionamentos amorosos como empreitadas de elevado risco e, talvez, com não tão significativos benefícios, vive-se em busca de se apossar do que é melhor em cada pessoa, a cada momento, numa dinâmica contraproducente à qualidade de qualquer relacionamento (Almeida, 2007a).
Todos nós cultivamos certo grau de ciúme. Afinal, quem ama cuida. Mas, como este desvelo pode variar na interpretação de uma pessoa para a outra, de forma análoga, o ciúme também variará. Portanto, o ciúme desenvolve-se quando sentimos que nosso parceiro não está tão estreitamente conectado conosco como gostaríamos (Rosset, 2004). O ciúme geralmente surge quando um relacionamento diádico valorizado é ameaçado devido à interferência de um rival e pode envolver sentimentos como medo, suspeição, desconfiança, angústia, ansiedade, raiva, rejeição, indignação, constrangimento e solidão, dentre outros, dependendo de cada pessoa (Daly \& Wilson, 1983; Haslam \& Bornstein, 1996; Knobloch, Solomon, Haunani, \& Michael, 2001; Parrott, 2001). Assim, segundo Ramos (2000) é possível se ter ciúme até mesmo em relacionamentos platônicos, em que há um amor unilateral não correspondido.

Dessa forma, o ciúme pode ser entendido como o medo que sentimos de algum dia sermos dispensáveis à pessoa com a qual nos relacionamos. Está presente com freqüência nas relações humanas, e, quando relacionado às relações diádicas-afetivas, isto é, aos casais, é denominado de ciúme romântico (Almeida, 2007a, 2007b; Bringle, 1995; Hansen et al., 1985; Harris, 2002; Salovey, 1986, 1989). É o sentimento de apreensão que cultivamos, relacionado à possibilidade de sermos abandonados, rejeitados, menosprezados, ou ainda, de haver uma infidelidade em andamento; é o receio de não mais sermos importantes; é o medo de não sermos mais amados; o medo de não possuirmos ou sermos donos de alguém; enfim, é o medo da solidão associado com o abandono dos parceiros (Ferreira-Santos, 2003). Neste sentido, o ciúme está relacionado à percepção de vinculação e de pertencimento do outro que, devido à presença de um rival (real ou imaginado), podem parecer ameaçados. Concordes a esta conceituação, para os autores Hintz (2003) e Branden (1998), o ciúme é uma emoção experimentada por um indivíduo que percebe que o amor, a afeição e a atenção do parceiro estão sendo encaminhados a uma terceira parte, quando julga que estas oportunidades deveriam estar sendo-lhes oferecidas.

Logicamente, devemos considerar os extremos: para diferentes pessoas, a ausência de ciúme pode ser tão perniciosa quanto seus excessos. Isso quer dizer que algumas pessoas se sentirão lisonjeadas com as manifestações mais efusivas de ciúme por parte do outro, enquanto que, para outras, até mesmo as mais modestas expressões ciumentas não são toleradas quando lhes são dirigidas. Portanto, o ciúme eclode das relações amorosas devido a fatores tais como comparação, competição e medo da substituição pelos rivais.

\section{Ciúme e características dos relacionamentos amo- rosos por ele afetados}

Várias perguntas podem ser formuladas sobre o ciúme: sua origem, sua intensidade, sua duração, a forma como a pessoa que o sente reage, a importância que ele assume no seu cotidiano, como ele interfere na vida de quem convive com a pessoa ciumenta, por exemplo.

Como mencionado anteriormente, o ciúme pode ocorrer em quaisquer tipos de relacionamentos, mas está comumente associado aos relacionamentos amorosos. Ainda que haja alguma controvérsia sobre a inerência do ciúme, pode-se inferir que o 
ser humano sente, não raramente, alguma forma de ciúme por algo ou por alguém nas diversas fases dos relacionamentos interpessoais que vivencia. Segundo Ferreira-Santos (2003) e Nogueira (2002), o ciúme pode ser considerado como uma manifestação normal das pessoas, umas em relação às outras, assim como é normal sentir medo, inveja, luto, alegria, raiva e saudade, dentre outras emoções humanas. Portanto poderia ser considerado um sentimento constitutivo da natureza humana, de maneira que todos nós seríamos ciumentos em maior ou em menor grau.

Porque tememos tal encontro do nosso parceiro com outros rivais potencialmente mais atraentes e gratificantes do que nós, freqüentemente, temos alimentada nossa insegurança. Dessa forma, o ciúme romântico não somente é um dos mais importantes temas que envolvem os relacionamentos humanos, bem como um desafio para muitos destes. Uma grande dificuldade ao se estudar o fenômeno do ciúme é o fato de que, para muitos, ainda, ele é uma manifestação de afeto, de zelo ou até de amor que uma pessoa sente por outra. Talvez isto seja mesmo verdade em algumas situações e, provavelmente, não, em muitas outras.

Muito tem sido escrito sobre esse fenômeno chamado ciúme, que tantas vezes se instala em nós e em quem amamos, e que nos priva da tranqüilidade, da concórdia e da confiança em relacionamentos que nos são caros. É importante falarmos a respeito de um tema como este porque provavelmente, em algum momento da vida, por ele seremos afetados ou porque o sentiremos, ou ainda, porque seremos vitimizados como alvo de uma pessoa ciumenta.

Para Clanton e Smith (1998), o adulto torna-se ciumento quando acredita que o casamento ou o relacionamento romântico no qual está inserido está ameaçado por um rival real ou imaginário. Levando-se em consideração o que foi apresentado anteriormente, pode-se dizer que as pessoas ciumentas permanecem ambivalentes entre o amor e a desconfiança de seu parceiro, tornando-se perturbadas, com labilidade afetiva e obcecadas por triangulações, muitas vezes imaginárias (Almeida, 2007b). Dessa forma, os ciumentos conflitam entre o medo de descobrir a infidelidade real dos seus parceiros, e, não constatando a infidelidade, descobrir que sofrem de uma forma de delírio de ciúme (Hintz, 2003). Ambas as situações são ruins, mas o pior é a incerteza da verdade. A partir disso, ocorre, freqüentemente, que o(a) parceiro(a) infiel coloca o outro em dúvida de suas próprias percepções e memórias. Algo que incomoda o indivíduo ciumento é seu parceiro negar a existência de outra pessoa e que sempre foi fiel e fazer com que ele(a) acredite que está imaginando coisas. Há casos que, após o parceiro ciumento descobrir a verdade a respeito da infidelidade, irritar-se mais com a mentira, que o fazia acreditar que ele próprio estava errado ou mesmo doente por imaginar coisas, do que a própria infidelidade (Hintz, 2003).

O ciúme romântico, assim como outros traços da personalidade, tal qual a timidez, dentre outros, pode ser influenciado por forças situacionais e/ou disposicionais. $\mathrm{O}$ situacional é um sentimento natural que surge diante de um acontecimento que apresente um perigo real de envolvimento do parceiro com um rival. No ciúme situacional o grau de ciúme varia, para a mesma pessoa, quando exposta a situações diferentes que apresentem diferentes graus de ameaça ao seu relacionamento (Bryson, 1977; Shackelford, Leblanc, \& Drass, 2000). O ciúme disposicional é aquele que varia entre as pessoas diante de uma mesma situação ameaçadora (Bringle, 1981; Cavalcante, 1997; Greenberg \& Pyszczynski, 1985).

Há ainda autores para os quais esse sentimento assume um volume monstruoso e desfigura e perturba a vida de ciumentos e de suas vítimas, de tal forma que não há mais sossego possível. São os casos em que o ciúme se torna patológico, doentio, e torna-se uma obsessão descontrolada e descontroladora (Cavalcante, 1997; Lazarus, 1993; Mathes, 1992).

Numa relação afetada pelo ciúme, as pessoas, geralmente, são reificadas, ou seja, tratadas como objetos pelos próprios parceiros. Muitas se anulam, e assim, perdem grande parte de sua identidade para serem o que o ciumento quer que sejam, tentando corresponder a todas as suas expectativas. Em tal caso, pode-se dizer que não há uma aceitação mútua. $\mathrm{O}$ que mascara esta constatação é a percepção distorcida de que isso é feito "altruisticamente" pela pessoa ciumenta, pelo bem do outro. Por esta perspectiva, o ciúme pode ser considerado fundamentalmente egoísta à medida que leva o seu possuidor a agir visando com isso tolher os direitos da pessoa a ela vinculada. Isto é, quando o ciúme se manifesta, não visa proteger o outro, como erroneamente costuma se pensar, e sim preservar a si mesmo de futuras preocupações que lhe sejam custosas em relação ao investimento amoroso realizado (Almeida, 2007a). Uma relação como esta pode ser caracterizada como doentia e destrutiva, na qual as pessoas se beneficiam umas das outras, ou ainda, servem-se do outro como uma forma de obter garantia de que não serão abandonadas, de que não serão desrespeitadas e menosprezadas (Ferreira-Santos, 2003).

A relação amorosa constitui-se enquanto um fenômeno de movimentos opostos, na qual o desprendimento e a admiração mútua resultam em uma forma do entendimento e da compreensão do casal estabelecido. Por este prisma, uma relação saudável seria aquela em que cada indivíduo tem a sua própria identidade e deseja fazer o bem à pessoa amada, sem esperar recompensa (Rosset, 2004).

Então, é por isso que muitas vezes, pode-se dizer que o ciúme destrói essas relações saudáveis e faz com que a pessoa sofra. O ciumento, muitas vezes, pode ser percebido como uma pessoa que tem baixa auto-estima e não consegue dar valor a si mesmo. Justamente por isso, é possível de ser traído e abandonado. Acredita na idéia de que pode ser traído de algum modo e conclui que a honestidade e a reciprocidade no relacionamento não valem à pena (Ferreira-Santos, 2003).

Segundo Rosset (2004), ciúme é um conjunto de emoções desencadeadas por sentimentos de ameaça à estabilidade ou qualidade de um relacionamento íntimo valorizado. As definições de ciúme são muitas, mas todas têm em comum três elementos: (1) é uma reação frente a uma ameaça percebida; (2) haver um rival real ou imaginário; e (3) a reação visa eliminar os riscos da perda da pessoa amada.

Dentro de certos limites, o ciúme pode constituir uma demonstração de preocupação e de interesse pelo outro, e sinalizar um reflexo desse amor (Almeida, 2007a). Evidentemente, o 
ciúme implica certo cerceamento do outro, porque o parceiro ciumento, de algum modo, interfere no comportamento do outro e em sua liberdade, tornando-se possessivo e controlador. Contudo, quando não há nenhum sinal de ciúme, deve-se ficar igualmente em alerta, e examinar se a relação não está se desgastando, e, portanto, tornando-se desprovida de amor, o que pode transformar este relacionamento amoroso em uma relação com características fraternas (Ferreira-Santos, 1998). Conseqüentemente, o ciúme romântico não somente é um dos mais importantes temas que envolvem os relacionamentos humanos, bem como um desafio para muitos destes. Dessa forma, várias ciências (Psiquiatria, Psicologia, Sociologia, Neurociências, dentre outras) procuram explicar quais as razões para alguém ser ciumento, mas nenhuma delas ofereceu ainda uma resposta definitiva.

O ciúme pode surgir depois que se é traído somente uma vez. E assim, pode-se relacionar a uma infidelidade consumada. A partir daí, ciumentos costumam presumir novamente quadros de infidelidade amorosa e a partir disso, passa a se generalizar a expectativa de infidelidade. O ciúme deste tipo é alimentado pela crença de que os parceiros passam a ser traidores em potencial, e dessa forma, começa o processo de vigilância constante e o surgimento de conflitos, velados ou manifestos.

O ciúme pode também estar relacionado a uma infidelidade presumida e ser fruto de uma profecia auto-realizadora de que haverá infidelidade amorosa entre os parceiros (Almeida, 2007a). Sabe-se que muitos dos nossos comportamentos são largamente influenciados, e até mesmo governados por normas e/ou expectativas que funcionam como diretrizes para que as pessoas se comportem de determinada maneira em certa situação.

Ao se refletir sobre expectativas que influenciam os comportamentos, pensa-se logo em profecias auto-realizadoras. Estas profecias são, em resumo, definidas como crenças capazes de exercer influência sobre aqueles que nelas crêem: as pessoas mudam de atitude e se engajam em comportamentos que aumentam as chances de ocorrer aquilo que crêem ou temem (Rosenthal \& Jacobson, 1968). Dessa forma, as pessoas não seriam inertes aos encontros interpessoais e tampouco estariam ilesas às expectativas ciumentas dos próprios parceiros em uma situação amorosa. Conseqüentemente, o outro teria a propriedade de modelar o nosso comportamento nas mais diversas circunstâncias.

Normalmente, as pessoas muito ciumentas monitoram constantemente os parceiros na tentativa de diminuir, ou mesmo, evitar que os mesmos possam vir a traí-las. Logo, ainda que sutilmente, tais expectativas podem influenciar o comportamento dos parceiros, aproximando-os de outras pessoas que anteriormente lhes passavam despercebidas $\mathrm{O}$ ciúme também pode estar relacionado ao acúmulo insidioso de conflitos e a uma possível perda de qualidade no relacionamento valorizado.

O que poderá ocorrer, por conseguinte, é que dada a presença dessa profecia (como uma hostilidade cumulativa dirigida ao parceiro que é suspeito de estar traindo), a pessoa que é objeto de ciúme acaba se engajando em comportamentos infiéis (Almeida, 2007a). Logo, o que ocorre é que a pessoa que se sente vigiada em tempo integral, torna-se ressentida e, este processo possivelmente abre caminhos para uma relação paralela, em que a compreensão e o respeito estejam mais presentes.

É preciso identificar os motivos que nutrem o ciúme para cada pessoa e utilizar suas manifestações como sinal de alerta. É importante que uma pessoa, ao perceber que está sendo tomada pelo ciúme, se dê conta disso, olhe para dentro de si e busque os recursos necessários para os cuidados do equilíbrio emocional e assim assegurar o bem-estar da relação. É necessário, também, conhecer esse fenômeno para que se saiba contorná-lo, vencê-lo e usá-lo como trampolim para uma realidade mais positiva no relacionamento conjugal.

Ferreira-Santos (2003) acrescenta que o ciúme é uma manifestação atrapalhada de vários elementos reprimidos no inconsciente, que se estende desde uma baixa auto-estima, até mesmo o sentimento de culpa por ter feito algo errado para o outro, passando por diversas possibilidades de transformação.

O ciumento duvida de si mesmo, assim como atribui ao outro uma série de desconfianças. O ciúme pode, portanto, ser considerado imaginário, porque toma a pessoa com a imaginação obsessiva de que pode estar sendo ameaçada de perda ou humilhação. A comprovação, em muitos casos, chega a atenuar o sofrimento. Como o ciúme reside na dúvida, no medo, quando há a certeza da infidelidade, o sentimento que aparece é outro. Pode ser raiva, depressão, desespero, mas não é mais ciúme, ou ainda, este pode aparecer simultaneamente a estas manifestações.

\section{O ciúme patológico (Síndrome de Otelo)}

Vemos na literatura inúmeros casos emblemáticos para a questão do ciúme. Um dos mais conhecidos é o drama Otelo-O Mouro de Veneza, de William Shakespeare. Em sua obra, o autor intitula o ciúme como o monstro dos olhos verdes. Nessa história, o protagonista, Otelo, envenenado de ciúme pelo astucioso Iago, deixa-se levar por um ciúme doentio, que envolve o seu melhor amigo e a sua esposa, e acaba matando a honesta, terna e doce Desdêmona. Observa-se que, no âmbito do ciúme, não é preciso haver provas para se acusar os parceiros e, tampouco, concluir a partir de fatos que validem as crenças ciumentas, a exemplo do Mouro de Veneza. As pessoas, sobremaneira as ciumentas excessivas, podem se pautar parcialmente na realidade e colecionar fatos que lhes conduzam a uma decisão baseada mais na forma distorcida como enxergam a realidade.

O conceito de ciúme mórbido ou patológico, também chamado de Síndrome de Otelo, em referência ao drama shakeasperiano, escrito por volta do ano de 1603, compreende várias emoções e pensamentos irracionais e perturbadores, além de comportamentos inaceitáveis ou bizarros (Leong et al, 1994). Envolveria muito medo de perder o parceiro para um rival, desconfiança excessiva e infundada, gerando significativo prejuízo no funcionamento pessoal e interpessoal (Todd \& Dewhurst, 1955). Esses casos estão cada vez mais acorrendo à clínica, onde casais buscam suporte para sua dinâmica conturbada por esse fenômeno.

O que aparece no ciúme patológico é um grande desejo de controle total sobre os sentimentos e comportamentos do companheiro. Há ainda preocupações excessivas sobre relacionamentos anteriores, isto é, ciúme do passado dos parceiros, as quais podem ocorrer na forma de pensamentos repetitivos, imagens intrusivas e ruminações sem fim sobre 
fatos de outrora e seus detalhes (Cavalcante, 1997). Esses sentimentos envolveriam um medo desproporcional de perder o parceiro para um rival (real atual, ex-parceiros, ou mesmo, rivais imaginários), desconfiança excessiva e infundada, o que provoca um significativo prejuízo no relacionamento interpessoal.

O ciúme patológico, então, corresponde a uma preocupação infundada, absurda e emancipada do contexto. Enquanto no ciúme não-patológico, o maior desejo é preservar o relacionamento, no ciúme patológico haveria o desejo inconsciente da ameaça de um rival (Cavalcante, 1997).

No ciúme patológico, várias emoções são experimentadas, tais como a ansiedade, depressão, raiva, vergonha, insegurança, humilhação, perplexidade, culpa, aumento do desejo sexual e desejo de retaliação. O portador do ciúme patológico é um vulcão emocional sempre prestes à erupção e apresenta um modo distorcido de vivenciar o amor, pois, para esta pessoa, o quadro que está sendo manifestado é uma contingência obrigatória do sentimento amoroso e, portanto, não passível de crítica. Esse paciente com ciúme patológico seria extremamente sensível, vulnerável e muito desconfiado, geralmente portador de autoestima muito rebaixada, tendo como defesa um comportamento impulsivo. Ainda que o ciúme seja valorizado pelas pessoas como uma forma de demonstrar apreço pela outra pessoa, de fato, para muitos casais, ele vem a ser um grande problema. E pode prejudicar seriamente a relação em questão. Segundo FerreiraSantos (2003), uma pessoa com auto-estima reduzida nutrirá por si mesma um forte sentimento de ansiedade e incerteza. Sentirá, dessa forma, que sua segurança depende do outro e do que imagina que as pessoas pensam a seu respeito. Isso geralmente enfraquece sua autonomia e individualidade.

Uma característica do ciúme bastante observada é o sentimento de frustração que acompanha o indivíduo, devido à sua baixa auto-estima e a sua insegurança. Rosset (2004) afirma que auto-estima é o sentimento da importância ou valor que a pessoa tem por si mesma, é o auto-respeito e autoconsideração. Ela é construída a partir das experiências que provam e comprovam a sua competência nos vários aspectos da sua vida.

Quando uma pessoa tem uma auto-estima rebaixada, provavelmente é tomada por fortes ilusões com respeito ao que pode esperar dos outros, tem tendência a abrigar fortes temores, além de ter uma forte predisposição para manifestar desapontamentos e desconfiar das outras pessoas. É muito comum que pessoas com baixa auto-estima escolham seus cônjuges para conseguir algo que lhes falta: pode ser a estima que esperam que o outro tenha por si; pode ser alguma qualidade que vêem no outro e sentem que lhes falta; pode ser o movimento e a ação que o outro faz e que espera que faça por si, entre outras hipóteses. É comum, também, que pessoas com baixa auto-estima, no relacionamento conjugal, estejam inclinadas a repetir ou ainda a fazer completamente o oposto do que viram entre os seus pais (Rodrigues, 2005).

A teoria sistêmica de Bowen (1978) se propõe a elucidar a tendência universal de buscar a fusão dos cônjuges. Esta teoria afirma que essa fusão está relacionada à incompleta diferenciação da pessoa em relação à sua família de origem. Em outras palavras, os casais buscam completar-se um no outro, na medida em que não conseguiram resolver anteriormente seus relacionamentos com os pais (Carter \& McGoldrick, 1995). No entanto, ainda segundo estes autores, há uma imensa diferença entre estabelecer um relacionamento íntimo com outra pessoa e servir-se de um relacionamento de casal para satisfazer a si mesmo e melhorar a auto-estima ou para modificar vivências observadas no relacionamento dos pais.

Segundo a abordagem sistêmica, uma pessoa com baixa auto-estima nunca se separou realmente dos pais, isto é, jamais conseguiu estabelecer, com eles, uma relação de independência.

No momento em que duas pessoas se juntam para ser um casal, elas constituem um sistema que passa a ser o subsistema conjugal. Assim, quando duas pessoas decidem se unir, o fazem porque resolvem que parece ser bom para elas tal arranjo. Somos seres gregários por natureza e, ao que parece, freqüentemente caminhamos ao encontro do outro aspirando por uma completude (Almeida, 2007b). Esse subsistema poderá ser o gerador de uma nova família; porém, mesmo que se encerre em si mesmo, será responsável pelo desenvolvimento e pelo crescimento emocional das duas pessoas envolvidas. Contudo, o fato de eleger uma pessoa para dedicar uma parte do seu tempo e dos seus recursos não implica que não se possa mudar de idéia posteriormente e, possivelmente, lesar, ou romper este subsistema constituído (Almeida, 2007b). O que é sintomático é o fato de que nem sempre esse contrato é compreendido por ambas as partes da mesma maneira. Embora isso possa nos parecer óbvio demais, continuamos a realizar rituais e a fazer promessas de amor eterno (Lemos, 1994).

Segundo Rosset (2004), ao enfatizar a psicodinâmica do relacionamento marital, o relacionamento conjugal exerce influência na natureza da homeostase familiar. Constitui o eixo em torno do qual se formam todas as outras relações familiares. A teoria sistêmica de Bowen (1978) trata o individuo como parte do sistema em que está inserido, que abrange todo o sistema fundamental que condiciona a vida desde os primeiros instantes do nascimento, ou seja, a família. Na visão sistêmica, a família ainda é vista como um todo que influencia as partes e, por sua vez, estas influenciam o todo. Nesse contexto, tanto o relacionamento conjugal quanto o crescimento individual, podem ser reconstruídos através da abertura de novas perspectivas de visão (Rodrigues, 2005).

No início de uma relação amorosa os indivíduos depositam nela um conjunto de desejos e expectativas que quase sempre lhes cegam parcialmente para a realidade. Mas, como pode se pressupor, a paixão é transitória, e a relação amorosa realmente começa quando se consegue sair de um aparente estado de transe e encarar a realidade tal como ela é. Então, um primeiro questionamento a ser feito se dá quando as pessoas investem em conhecer o outro. Entretanto, se as pessoas não têm um conhecimento prévio de si mesmas, algumas vezes, no relacionamento amoroso, há uma mistura e confusão quanto à contribuição de cada parceiro e isso pode desembocar em alguns conflitos desnecessários (Araújo, 2003).

Os vínculos considerados simbióticos, como analogamente aqueles configurados na situação em que um ciúme excessivo se manifesta, ou seja, quando uma pessoa vive em função da outra, 
podem ser considerados doentios. É como se o resto do mundo não existisse, pois a pessoa passa a não mais se preocupar com ela própria, com sua vida, com sua profissão, com seu círculo de amizades e permanece constantemente prestes a exercer o controle sobre o outro.

É muito comum que alguém espere do outro uma reação ciumenta de vez em quando, com o intuito de testar se ainda existe afeto recíproco ou algo mais. Dessa maneira, toda relação amorosa, a princípio, pressupõe um grau de ciúme saudável, por assim dizer. Nesse sentido, uma total apatia, segundo o que raciocinam muitos casais, pode revelar desinteresse, que para alguns representa um pesadelo mais indesejável do que ter um parceiro ciumento. O problema é quando se considera que o oposto do ciúme é a total insensibilidade ou apatia, pois nesse ponto, perde-se grande parte da noção de equilíbrio numa relação, atuando apenas os limites extremos; ciúme excessivo ou negligência.

A questão do ciúme ainda remete ao medo de elaborar a perda do parceiro, ou, ainda, à perda da qualidade do relacionamento tal qual a pessoa ciumenta presumia ter, e em última instância, ao medo da morte. Esses sentimentos sempre estão mais presentes em pessoas marcadas por experiências de abandono ou desamparo, sendo que qualquer relação dispara esse conteúdo descrito. Se realmente as pessoas querem que uma relação tenha êxito, elas devem se preocupar não apenas com os perigos da mesma, mas, principalmente, quando tomam emprestados poderosos sentimentos humanos destrutivos, que ao contrário de aprofundarem a intimidade, o comprometimento e o desejo de manutenção da relação, corroem por completo algo que poderia ter um desfecho de harmonia e prazer (FerreiraSantos, 2003).

Segundo Nogueira (2002), as pessoas recalcam os seus sentimentos de ciúme como uma forma de se adaptar a ele e conviver com o problema, e reprimem qualquer expressão que o denote. Nogueira (2002) afirma também que se tentou até hoje sanar o problema tratando da pessoa como um doente, ao invés de se buscar a origem deste sentimento. Por essa razão, na prática, as terapias de casais com problemas de ciúme e de suas nefastas conseqüências para os relacionamentos amorosos, muito pouco ou quase nada produzem, e não ofereceram nada de concreto para solucionar este problema. Ainda que o ciúme seja valorizado em uma dimensão social, que acredita que pode ser uma demonstração de amor, na verdade, em muitos casais ele se torna um grande problema. E pode até mesmo sucumbir o relacionamento em questão.

Freud (1922/1995) acreditava que a escolha do outro se fundamentava na opção por alguém que se parecia conosco, ou ainda, como gostaríamos de ser, ou até mesmo, de alguém que representou um papel importante em nossas vidas, como a figura paterna ou materna. Almeida (2003) afirma que este raciocínio pode ser considerado perigoso na medida em que, caso seja verdadeiro, são impostos ditames de conduta e padrões de comportamentos reparatórios que não se aplicam ao relacionamento atual. Conseqüentemente, ambos os parceiros ficarão frustrados, pois a expectativa de que o outro venha a suprir as experiências afetivas que cada um viveu ou fantasiou ter vivido, será sempre maior do que o(a) parceiro(a) pode realmente realizar.

Geralmente, quando se pensa no ciúme, costuma-se refletir sobre os seus excessos e suas conseqüências negativas para os relacionamentos amorosos. Entretanto, o ciúme não tem somente funções negativas, retaliadoras e hostilidades para o parceiro, e que podem colaborar para o desgaste da relação (Almeida, 2007b). Segundo Rosset (2004), o ciúme pode ser positivo e necessário. Em seu lado positivo, ele seria a consciência de um distanciamento ou de uma interferência numa relação de compromisso. Em geral, este benefício aparece quando o cônjuge sente que o parceiro não está tão ligado a ele como gostaria. Então, é uma indicação de que alguém ou alguma coisa se interpôs entre ambos e os vínculos se tornam mais frágeis. Dessa forma, muitas pessoas vão fazer uma tentativa de investir mais em si e em seus parceiros quando percebem uma ameaça para a unidade do relacionamento (Almeida, 2007a, 2007b). O ciúme também pode ser entendido como um sinal de alerta. Uma espécie de sinalizador a indicar que algo malogrou. Seja em um ou no outro parceiro, seja na relação, algum distanciamento é denunciado pelo ciúme. Quanto mais intenso e menos controlável, maior o problema advindo do mesmo.

Muitas pessoas idealizam os relacionamentos amorosos, mas poucas pessoas sabem que o vínculo amoroso, para diferentes pessoas, é construído no cotidiano, que vai se consolidando no dia-a-dia (Almeida \& Lourenço, 2007; Almeida \& Oliveira, 2007). É uma questão de convivência diária, é um sim que se renova, um contínuo compartilhar de uma vida em comum que começa a partir de algum ponto (Amélio \& Martinez, 2005). Dessa maneira, o ciúme, conforme pontua Rosset (2004), pode ser benéfico, sobretudo, se ocorre em uma união consistente e provoca um comportamento de aproximação dos companheiros. Algumas manifestações tênues de ciúme podem funcionar como uma estratégia que une o casal e previne qualquer tendência natural ao afastamento. Entretanto, quando o ciúme excede os limites do bom senso, ele provoca sofrimento para as pessoas envolvidas. Assim, é até possível que conduza ao término da relação.

O ciúme pode ser demasiado por várias razões. Em se tratando de relacionamentos de longo prazo, como casamentos, a primeira delas é uma interação matrimonial perturbada. Nesse caso, trata-se de casais que funcionam fundamentados numa psicodinâmica de "estar no controle", entre outros padrões que dão lugar à escalada cada vez maior de crises ciumentas.

Uma segunda razão para este sentimento são os contratos mal feitos, em que aspectos importantes não são verbalizados, desejos não são explicitados, restrições não são negociadas. Embora muitas vezes os parceiros concordem aparentemente com este "contrato" automaticamente, ele se forma a partir de uma, por vezes, extensa negociação que os componentes desse casal entabulam desde os primeiros encontros (Almeida, 2007b). Essa negociação acontece e se atualiza na medida em que diversas situações surgem no relacionamento. Isso leva freqüentemente a crises repetitivas e profundas na relação.

A terceira razão são dificuldades emocionais particulares de cada um dos parceiros. Indivíduos com sérias deficiências em sua estruturação de personalidade terão menos habilidades para lidar com relacionamentos e com todas as vertentes "perigosas" 
que existem, como desacertos, rejeições, desavenças. Podem ainda se sentir perseguidos e traídos, o que alimenta o excesso de ciúme (Rosset, 2004). Para a pessoa que costuma refletir a respeito dos próprios sentimentos, o se sentir dominado pelo ciúme a leva a questionamentos sobre este fenômeno e sua maneira de se relacionar amorosamente. Pode tirar conclusões importantes a respeito de sua forma de ser.

Em questão de ciúme, a linha divisória entre imaginação, fantasia, crença e certeza se torna vagas e imprecisas. As dúvidas podem se transformar em idéias supervalorizadas, ou ainda, delirantes. A pessoa é compelida à verificação compulsória de suas dúvidas. Ciumentos, entre outras atitudes, têm comportamentos obsessivos como a confirmação de onde o parceiro ou a parceira está, e se está mesmo com quem disse que estaria, abrir correspondências e ouvir telefonemas, examinar bolsos, bolsas, carteiras, recibos, e roupas íntimas. Seguem o companheiro ou a companheira. Até contratam detetives particulares para vasculhar o cotidiano dele ou dela. Toda essa tentativa de aliviar sentimentos, além de ser vista como ridícula pelo(a) próprio(a) ciumento(a), não ameniza o mal-estar da dúvida.

\section{O ciúme e os relacionamentos entre os casais}

Segundo Fischer (2006), o ciúme é uma reação adaptativa, uma vez que homens e mulheres captam sinais genuínos de que o relacionamento está prestes a fracassar. Isto seria útil porque aqueles que permanecem com parceiros descompromissados, terão menos oportunidades de conseguir parceiros mais adequados, além de diminuírem as possibilidades de propagar sua descendência. Uma completa ausência de ciúme é danosa para um relacionamento amoroso, por geralmente implicar numa baixa adesão de pelo menos uma das partes envolvidas. Fischer ainda argumenta que o ciúme pode estimular uma pessoa a acalmar o(a) parceiro(a) desconfiado(a) com declarações de fidelidade e de vinculação, contribuindo para a durabilidade do relacionamento.

Rosset (2004) estabelece que o ciúme é um tipo de projeção para a infidelidade amorosa, ou seja, a pessoa acusa o outro de desejar o que ela própria gostaria, porém sempre nega tal fato, seja por culpa, vergonha ou orgulho. Entretanto, em outro estudo, Almeida (2007a) não encontrou quaisquer correlações entre o ciúme de um parceiro e as próprias infidelidades como prediz esta outra autora.

\section{Considerações finais}

Ao concluir este estudo podemos identificar as várias formas de entender o ciúme, esse fenômeno tão complexo, tão repleto de interpretações. Talvez possamos considerar o ciúme não apenas como um sentimento, mas como uma construção social que abrange vários outros sentimentos como amor, ódio, medo, raiva, orgulho, inveja e que desencadeia idiossincraticamente reações diferentes, reais ou imaginárias, podendo ser ou não acompanhada de outro sentimento: a baixa auto-estima.

Pode-se ainda perceber que o ciúme é normal, embora sempre tenha uma origem mais profunda, inconsciente, e seus diferentes graus de manifestação podem ocorrer de acordo com a personalidade do enciumado e também do seu grau de auto-estima. E isso pode estar influenciado pela forma como aprendemos a lidar com o ambiente e com o nosso comportamento.

Também pudemos perceber que quando um membro da família sofre com o ciúme, enquanto vítima ou algoz do mesmo, isso acabará por alterar toda a família, todo o sistema, e à medida que o ciúme representa uma ação agressiva a uma perda efetiva ou ameaça de perda, quase sempre ele carrega consigo um sentimento de abatimento, pela afronta à nossa auto-estima e à sensação de segurança. De qualquer forma, o ciúme geralmente pode ser entendido como um sinal de alerta de que algo não vai bem, seja no relacionamento conjugal ou no relacionamento com nós mesmos.

O ciúme tem uma amplitude e uma profundidade que assinala que algo precisa ser observado em nossos relacionamentos. Não admiti-lo é perder uma grande oportunidade para a reflexão e, provavelmente, para a possível recuperação de um relacionamento que possa estar se esgotando, por conta de uma série de motivos, no qual o principal deles é a convicção distorcida de que sentir ciúme em demasia é estar zelando pelo outro.

A questão do ciúme perde-se em uma intrincada rede, derivada do desejo humano pelo controle absoluto, pela inalterabilidade das circunstâncias e pela inefabilidade do outro e de si mesmo, e embora o ciúme seja um tema recorrente trazido pelos casais em terapia, a produção de pesquisas sobre o ciúme ainda é bastante escassa. Observa-se a falta de instrumentos para que as pessoas possam conhecer mais e trabalhar essa questão que gera tantas dúvidas e questionamentos e que envolve tantos sentimentos durante os relacionamentos amorosos, quaisquer que estes sejam. Não obstante esta limitação, acreditamos útil e oportuna a divulgação deste trabalho na medida em que poderá contribuir para a realização de outros estudos que visem aumentar e/ou verificar a generalidade dos estudos acerca deste tema.

\section{Referências}

Almeida, T. (2003). O perfil da escolha de objeto amoroso para o adolescente: possiveis razões. Trabalho de conclusão de curso de Psicologia nãopublicado, Universidade Federal de São Carlos, São Carlos, SP.

Almeida, T. (2004). A gênese e a escolha no amor romântico: alguns princípios regentes. Revista de Psicologia (Fortaleza), 22, 15-22.

Almeida, T. (2007a). Ciúme romântico e infidelidade amorosa entre paulistanos: incidências e relações. Dissertação de mestrado não-publicada, Universidade de São Paulo, São Paulo, SP.

Almeida, T. (2007b). Ciúme e suas conseqüências para os relacionamentos amorosos. Curitiba: Certa.

Almeida, T., \& Lourenço, M. L. (2007). Envelhecimento, amor e sexualidade: utopia ou realidade? Revista Brasileira de Geriatria e Gerontologia, 10, 101-113.

Almeida, T., \& Mayor, A. S. (2006). O amar, o amor: uma perspectiva contemporâneo-ocidental da dinâmica do amor para os relacionamentos amorosos. In R. R. Starling \& K. A. Carvalho (Orgs.), Ciência do comportamento: conhecer e avançar (vol. 5, pp. 99-105). Santo André: Esetec.

Almeida, T., \& Oliveira, H. C. (2007). A importância e a banalização do amor no cotidiano. In Anais da V Jornada APOIAR: Saúde mental nos ciclos da vida (pp. 120-135) [CD-ROM. São Paulo: Universidade de São Paulo.

Amélio, A., \& Martinez, M. (2005). Para viver um grande amor. São Paulo: 
Gente.

Araújo, D. R. D. (2003). O amor no feminino: ocultamento e/ou revelação? Estudos de Psicologia (Natal), 8(3), 469-477.

Bowen, M. (1978). Family theory in clinical practice. Nova York: Aronson.

Branden, N. (1998). A psicologia do amor: o que é o amor, por que ele nasce, cresce e às vezes morre (M. Braga, Trad.). Rio de Janeiro: Rosa dos Tempos.

Bringle, R. G. (1981). Conceptualizing jealousy as a disposition. Alternative Lifestyles, 4, 274-290.

Bringle, R. G. (1995). Romantic jealousy. Social Perspectives on Emotion, 3, 225-251.

Bryson, J. B. (1977). Situational determinants of the expression of jealousy. In H. Sigall (Coordenador), Sexual jealousy. Simpósio apresentado no Encontro da Associação Americana de Psicologia, São Francisco, Califórnia.

Buss, D. (2000). A paixão perigosa - por que o ciúme é tão necessário quanto o amor e o sexo (M. Campelo, Trad.). Rio de Janeiro: Objetiva.

Carter, B., \& McGoldrick, M. (Orgs.). (1995). As mudanças no ciclo de vida familiar: uma estrutura para terapia familiar. Porto Alegre: Artes Médicas,

Cavalcante, A. M. (1997). O ciúme patológico. Rio de Janeiro: Rosa dos Tempos.

Clanton, G., \& Smith, L. G. (1998). Jealousy. Nova York: University Press of America.

Daly, M., \& Wilson, M. (1983). Sex, evolution, and behavior. Belmont: Wadsworth

Ferreira-Santos, E. (2003). Ciúme: o medo da perda. São Paulo: Claridade.

Fischer, H. (2006). Por que amamos. Rio de Janeiro: Record.

Freud, S. (1995). Más allá del principio de placer. Psicología de las masas y análisis del yo y otras obras (1920-1922). Obras completas de Sigmund Freud (pp.213-217). Buenos Aires: Amorrortu. (Texto original publicado em 1922)

Greenberg, J., \& Pyszczynski, T. (1985). Proneness to romantic jealousy and responses to jealousy in others. Journal of Personality, 53, 468-479.

Hansen, G. H., Buunk, B., Falus, G., Fulgosi, A., Ortega, E., Swain, R., \& Tarabrina, N. V. (1985). Romantic jealousy and romantic envy: a seven nation study. Journal of Cross-Cultural Psychology, 16, 423-446.

Harris, C. R. (2002). Sexual and romantic jealousy in heterosexual and homosexual adults. Psychological Science, 13, 7-12

Haslam, N., \& Bornstein, B. H., (1996). Envy and jealousy as discrete emotions: A taxometric analysis. Motivation and Emotion, 20, 255-272.

Hintz, H. C. (2003). O ciúme no processo amoroso. Pensando Famílias, 5(5), 45-55.

Kingham, M., \& Gordon, H. (2004). Aspects of morbid jealousy. Advances in Psychiatric Treatment, 10, 207-215.

Knobloch, L. K., Solomon, D., Haunani, C., \& Michael G. (2001). The role of relationship development and attachment in the experience of romantic jealousy. Personal Relationships, 8, 205-224.

Lazarus, R. S. (1993). From psychological stress to the emotions: a history of chancing outlooks. Annual Review of Psychology, 44, 1-21.

Lemos, P. (1994). Educação afetiva: Porque as pessoas sofrem no amor. São Paulo: Lemos.

Leong, G. B., Silva, J. A., Garza-Trevino, E. S., Oliva Jr, D., Ferrari, M. M., Komanduri, R. V., et al (1994). The dangerousness of persons with the Othello Syndrome. Journal of Forensic Sciences, 39, 1445-1454.

Mathes, E. W. (1992). Jealousy: the psychological data. Lanham, Maryland: University Press of America.

Melamed, T. (1991). Individual differences in romantic jealousy: The moderating affect of relationship characteristics. European Journal of Social Psychology, 21, 455-461.

Murray, S. L., \& Holmes, J. G. (2000). Seeing the self through a partner's eyes: why self-doubts turn into relationship insecurities. In A. Tesser, R. B. Felson, \& J. M. Suls (Orgs.), Psychological perspectives on self and identity (pp. 173-198). Washington: American Psychological Association.

Nogueira, J. A. (2002). Ciúme - uma nova concepção. Rio de Janeiro: Fundação Biblioteca Nacional.

Parrott, W. G. (2001). Emotions in social psychology: essential readings. Philadelphia: Psychology Press.

Pines, A. M. (1998). Romantic jealousy: causes, symptoms, cures. Nova York: Routledge.

Pines, A. M., \& Aronson, E. (1983). Antecedents, correlates, and consequences of sexual jealousy. Journal of Personality, 51, 108-134.

Ramos, A. L. M. (2000). Ciúme romântico: teoria e medida psicológicas. São Paulo: Stiliano.

Rodrigues, K. R. B. (2005). Ciúme: sintoma das crises conjugais. Monografia de conclusão de curso não-publicada, Universidade de Rio Verde, Rio Verde, GO

Rosenthal, R., \& Jacobson, L. (1968). Pygmalion in the classroom: teacher expectations and pupil's intellectual development. Nova York: Holt, Rinehart $\&$ Winston.

Rosset, S. M. (2004). O casal nosso de cada dia. Curitiba: Sol.

Salovey, P. (1986). The differentiation of social-comparison jealousy and romantic jealousy. Journal of Personality and Social Psychology, 50, 1100-1112.

Salovey, P. (1989). Envy and jealousy in close relationships. In C. Hendrick (Org.), Close relationships: review of personality and social psychology (pp. 221-246). Newbury Park, California: Sage.

Shackelford, T. K., LeBlanc, G. J., \& Drass, E. (2000). Emotional reactions to infidelity. Cognition and Emotion, 14, 643-659.

Todd, J., \& Dewhurst, K. (1955). The Othello Syndrome: a study in the psychopathology of sexual jealousy. Journal of Nervous and Mental Disorder, 122, 367-374.

Thiago de Almeida é doutorando em Psicologia Clínica pela Universidade de São Paulo. E-mail: thalmeida@usp.br

Kátia Regina Beal Rodrigues, psicóloga pela Universidade de Rio Verde, é professora de Psicologia Aplicada do SENAC e Colégio Sena Aires, em Rio Verde, GO. E-mail: katiabeal@globo.com

Ailton Amélio da Silva, doutor em Psicologia Experimental pela Universidade de São Paulo, é professor no Departamento de Psicologia Experimental do Instituto de Psicologia da Universidade de São Paulo. E-mail: ailton@uol.com.br 